\title{
Esse homo or esse kiborg: Anthropologic perspective in the information technology world
}

\author{
Sergey Lebedev ${ }^{1}$, Vera Lobastova $^{1 *}$, Oleg Samylov ${ }^{2}$, and Tatyana Simonenko ${ }^{1}$ \\ ${ }^{1}$ Saint Petersburg State University, the Institute of Philosophy, 199034 Universitetskaya \\ Naberezhnaya 7/9, Russian Federation \\ ${ }^{2}$ Emperor Alexander the $1^{\text {st }}$ Saint Petersubrg State Transport University, Economics and Management \\ Department, 190031 Moskovsky pr. 9, Russian Federation
}

\begin{abstract}
The article traces a transition from non-classical understanding of the digital world as reality created by people to develop tools for resolution of theoretical and practical tasks to postnonclassical awareness of information space as distant from people. It has been shown that the digital reality arising out of the subjective world of people and increasingly acquires independent and self-sustaining existence. The information revolution expands the artificial world as interactive and makes actual a new type of interaction of a human being with the world, with himself or herself and other people. Interpersonal communication acquires a digital nature and loses direct connection with certain people dealing with a great number of technical gate-keepers. A man begins to form a template, fragmentary mind-set, which blunts the criticality and reflectivity in perceiving the world. All this makes the education a priority in the development of society, clearly defines its targets related to the formation and development of human potential for each subject of education.
\end{abstract}

Within the bounds of classical philosophic paradigm the virtual reality cannot be set aside as the one with its own existence, in non-classical (for example, phenomenological) one the digital world is a reality, that is created by a subject based on his or her theoretical and practical goals and tasks bearing both personal and common to humanity nature. The postnonclassical type of rationality offers the virtual world to be reviewed as an objective, independent and self-sustaining reality. This analytic logic of virtual (or digital, information) space is by no means chosen randomly.It reflects the real process of forming a new type of reality, its place and meaning in human life.

At first thought, a significant and inherent property of the digital world is its stable relatedness to a subject, who makes the digital reality possible because only a subject can determine the existential authenticity of the digital world. In this situation, no matter how global and all-encompassing it seems to be the digital world as part of immanent experience of a subject cannot overshadow and thus substitute the physical world and quite a different situation develops when this immanent experience actively starts to multiply and unfold in an endless perspective of various options for intesubjective interactions.

\footnotetext{
*Corresponding author: hist@pgups.ru
} 
To understand true reality of the digital world in a more precise and clear manner we should turn to a phenomenological model of consciousness in order to describe the structure of conscious activity in more detail and thoughtfully as Edmund Husserl did in his transcendental-phenomenological philosophy. The fundamental property of consciousness, which makes conscious activity itself possible, is its intentionality. According to this property every act of consciousness is directed at something and tries to capture this something and hold as an object experiencing and perceiving it in various ways available to consciousness here and now.

All conscious activity of a subject is encompassed by an intentional approach of this consciousness to a variety of intentional objects, which make up a vast field of his or her immanent experience. According to Frantz Bretano's standpoint, who in his descriptive psychology applied the principle of intentionality to analyze the structure of consciousness, there is no and there cannot be objectless consciousness and unconscious experiences [1]. In the act of reflectivity a subject directly finds himself or herself existing only when he or she notices that something happens to him or her. For example, when a subject perceives assumingly, sees something, some object, he or she simultaneously realizes that it is him or her who experiences this something, some object in his or her perception but not any other individual.

Each object experienced in consciousness is located in the intentional act as its integral part. The intentional act arising out of consciousness and identifying active conscious activity of a subject puts its object into the immanent field of experiences thus making it part of consciousness. An intentional object in the act of experience becomes dependent, because it is correlatively linked with consciousness and cannot exist beyond consciousness. A subject obviously experiences the existence of this intentional object in the sphere of immanent experience and also experiences the actual existence of his or her consciousness on the whole, in its unity.

Consciousness is a single stream of intentional acts continuously running one after another in synthetic relations with different level of complexity and flowing within the allencompassing internal time of a subject. E. Husserl emphasized:-"On two sides, psychology is an unlimited flow of phenomena with a single intentional line passing through it, which would seem to be a list of all-encompassing unity, namely the line of immanent time without beginning and end- the time that cannot be measured by any chronometers" [2].

Intentional acts differ by types in accordance with the methods intentional objects are given to one's consciousness. So experiences can include sensory perceptions, memories, imaginations, speculations, desires, assessments, interest and emotions. An intentional object is always given to consciousness as an important one to it; it is experienced not only in isolation as all by itself but also in the open space of previous and further intentional acts. The single immanent experience of consciousness is passed through in a flow of interchanging ways of a given in particular as defined and undefined, contemplating and non-contemplating and only assumed methods. Intentional objects can also be experienced by a subject in different existential modalities such as actual, doubtful and others. This demonstration of various changeable methods of a given for intentional objects results in synthetic interrelation, which constitutes immanent experience of a subject as unified, and single and permanently existing one for consciousness. The virtual reality is an expression and exemplification of this stable interaction.

The action of consciousness manifests itself in its constituting activity, the backbone if which consists in assigning such a meaning to an intentional object that is used by a subject to experience this object in consciousness. This meaning assumed by a subject still requires a procedure for multiple repetition and adequate confirmation. This procedure is implemented in a continuous flow of harmonized intentional acts. The unity of a subject's 
immanent experience extends much further of separate and single intentional objects because any intentional act can be surrounded by others still being hidden and able for actualization by experiences.

After conducting clarifying phenomenological reductions in the sphere of a subject's immanent experience it is possible to clearly distinguish the two levels of experiences empirical and transcendental. Empirical experiences fill up the psychophysical structure and exist in an individual, random and doubtful way. Transcendental experiences make up the eidetic structure and demonstrate the universal, necessary and apodictic status of existence. A transcendental subject takes the central position of his or her immanent experience and surrounded by a great deal of intentional objects. Close and remote location of intentional objects depends on the degree of actuality and significance to a subject.

Alongside with own primordial experience a subject notices other psychophysical structures with independent existence. In the act of appresentation or comparing apperception a subject conceives other subjects having the same structure of consciousness, which is although not accessible to him or her. Subjects form the intersubjective world based on communicative experience. "The ego is no longer an isolated thing alongside other such things in a pre-given world. The serious problem of personal egos external to or alongside of each other comes to an end in favor of an intimate relation of beings in each other and for each other" as quoted by E. Husserl [2]. In a process of various verbal and non-verbal interactions subjects through joint efforts constitute intentional objects being common to them, harmonizing and enriching the immanent experience of each subject participating in the intersubjective world. The digital world's resources used to accumulate information and expand contacts are applied here.

Digital technologies are first of all a tool. A man always depends on something - on external physical reality, on communication with other people and on their internal world. The well-being is acquired by him after successful influence on these areas. This well-being is stated by consciousness in the form of experiencing the states of happiness, pleasure, enjoyment etc. Internal states are the initial point of human activity and its ultimate goal. Therefore, the internal sphere of human brain has the signs of self-sustainability, although, needless to say that a finite creature can have it slightly deferent. People would certainly not have been people if they had neither developed tools nor accumulated technologies to interact with reality. The more primitive a tool is the more it is connected with the body and the more obvious it plays a utility role and does not lay claim for something more. Tools used to influence the physical world are perceived by the human consciousness as just tools that cannot substitute the content of internal experiences.

Technical capabilities at the end of the 20th century allowed people to realize and automate one of their intellectual functions - a calculating function by developing appropriate machines. A tool being primarily internal one in the past is being detached now and takes on the form of an external device being accessible to any individual. Those who are busy making IT-equipment more complex should enhance their intellectual abilities and skills and those who do not have to deal with computations may get relaxed and enjoy machine capabilities. There are preconditions being developed for intellectual stratification of society and degradation of its majority and as it usually happens this does not set off alarm bells straight away.

The simulation and objectivization of rational calculating ability is still a tool, which is not self-sufficient performing a utility function. But transiting to the simulation of visual and sound images has actually become a move not only to the simulation of intelligence but the entire human mental life. The tool function ceases to be noticeable. A picture on the screen allows people to minimize contact with reality and build up their own virtual external world in conformity with offered rules and inherent tastes. The choice of virtual reality provides people with a distorted image of physical reality; the simulation that 
pictures the physical world more beautiful in many cases than it is in reality and has a better position compared to the original. The physical world's illusion created by digital technologies inside consciousness is no less real for this consciousness than the physical world itself (which by the way is not the physical world in itself but only its psychic and intellectual image). Why do people need to come out of the world's image where they can do almost everything into the world where they can do almost nothing? Easy solutions to the problems take on the form of speedy search of ready answers in the internet. Another individual comes out as a network chat name and communication with him or her is limited to an exchange of short information between chat names. Digital technologies in contrast to others to a greater extent detach an individual from physical reality from the necessity to communicate with other individuals. The tool becomes an individual's "other self". If people still remain to people physically then their consciousness exists under the laws of digital reality.

As a result the digital reality takes on a number of properties overriding the inherent subjective world of its separate users. Self-sufficiency, self-sustainability and selfdeterminacy are among the digital world's acquired characteristics. Gradually the virtual world containing a sphere of information technologies introducing algorithms and thus making the intellectual process easier due to its tool attractiveness and visible variety practically captures and absorbs the human world completely, brings it under control of its logic and its laws.

This situation is reflected in a philosophical discussion over the recent years. So in modern ontology the understanding of existence as a subject-to-object interaction gives way to the concepts in which this subject-to-object interaction gives place to objectoriented ontology. As an example, we can give Graham Harman's immaterialism concept, which debates traditional European ontology. For Harman objects are- "sleeping giants holding their forces in reserve and do not unleash their energies at once" [3]. The world according to Harman is similar to Parmenides' cosmic space - "one homogeneous existence on one side and an unreliable game of opinions and visions on the other side" [3]. The world of subjects and objects is undermined following the information revolution and establishing a new type of people's interaction with the worlds and each other. The philosophical topics of virtual object ontology have been developed since recently by the Centre of Virtualistics attached to the Institute of Human Studies (Russian Academy of Science). If the first studies of virtual reality were about an analysis of mental state and mental training in conditions of extreme situations [4] then further on this analysis picked up philosophical aspect as well $[5,6]$. It is emphasized in a philosophical analysis of virtual reality that virtual objects characterize "creation, actuality, self-sustainability" [5], that the world in aspect of virtual paradigmatics is polyontolodical, each created virtuality does not exist forever but in a situation of its action or interaction - interactivity and there is "another reality" existing objectively [5]. This new reality is characterized by a huge informative component with exclusive self-sustainability makes it possible to form special types of culture and education. Modern education involving the maximum amount of certain knowledge as one of its actual tasks cannot but use new computer-based telecommunication technologies that are used to create a well-ordered and transparent world image. Therefore, developing new methods for transfer of knowledge and its permanent transformation is an objective and inevitable process.

First of all let us indicate the characteristics of knowledge itself as an educational phenomenon. According to a representation widely spread in philosophy knowledge bears a true educational meaning only in that case when its object is included in human activity in a human co-being system representing an event for him or her because the objectness is not only the characteristic of objective reality, it is the characteristic of consciousness itself preconditioned by expanding the boundaries of its activity. As noted, for example, S.L. 
Frank to a large extent following the logic of phenomenological trend in philosophy, the object is not a transcendental object beyond consciousness but the moment of objectness in consciousness itself, in which some contents of our consciousness take on an objective nature for us"[7]. However, the continuously growing flow of information perceived by people is far away for its educational meaning to be recognized: As a result knowledge is obtained without objective values. The thing is that as a rule it reflects simulated phenomena having no place in reality, what is more important is that human consciousness loses its objectness because the global, unified reality absorbing it does not consider understanding and acceptance of cultural diversity, emotional-active attitude towards the sociocultural contest of knowledge being. Knowledge becomes plain and ethically neutral.

Being captured by virtual reality, which becomes increasingly understandable, actual and interactive, close and more preferable than actual reality, people have less abilities for creative work, who cannot and do not want to evaluate or create something really new. The goals of education correspond to this position of things: They shift towards the training of not only specialists being able to resolve creative tasks and reproduce knowledge but successful users of information cyberspace, in other words, the tasks of educations only unless they are comprehended on the ground of spiritual positions mostly have a tool orientation.

Due to the total effects of a new reality on human consciousness, people lose critical and reflexive properties in perceiving the world and form template, fragmentary thinking, which makes it impossible to consider knowledge as the most important side of human life connected through diverse meanings and demonstrations with the physical, natural world on one side and with the world of human feelings and relations on the other side. This tendency in the development of modern education becomes more relevant, this what O.D Shipunova and L.I Evseeva write about in their article: "A hyperactive communicative network is capable of transforming the informative field and message meanings thus creating potential conditions for destructing the commonality and mental structures of collective, unconscious, practical and discursive consciousness" [8].

As a result of total influence the information environment have on people the nature and style of communication are changed within the educational space. The quantitative indicators - speed and volume of messages transferred from a network to a user and back are a criterion of success in the sphere of information technologies. As for interpersonal communication, its conceptual certainty and completeness then it clearly undergoes transformation becoming multiple-valued, digital and dependent on an endless succession of various virtual intermediate carriers and as a result - not quite directed at an individual subject. That is why a user loses his or her meaning as a human subject -feeling, worrying, reasonable and spiritual, which completely changes the educational situation. In this new information reality everything is done to make a man passive, personally primitive, not being able for truly reflexive activity, which is born exclusively out of communication and live exchange of knowledge, opinions, impressions with the world as well as in the process of active attention towards self ego.

Reflections on a new reality created by people, which becomes more and more detached from them and begins to stand against them, inevitably bring worries over the prospects of humanity. A well-known statement "Esse homo" becomes irrelevant. In conditions, when the real human world is being replaced by the artificial world absorbing and substituting everything in people that is attributed to humanity - mind, feelings, worries, will, freedom, creative works, love and when a man becomes part of the digital reality, its appendage a future man's new image "Esse kiborg" is being developed, because the anthropological perspective moves in this direction. Despite the objective nature of this process, it can and must be counteracted. For this purpose, society has an excellent tool - a system of education, which is developed in accordance with the objectives and tasks of social 
developmet. These objectives are important to perceive and articulate clearly and take as a basis of modern educational paradigm.

\section{References}

1. F. Bretano, Selected works (House of the intellectual book, Moscow, 1996)

2. E. Husserl. Logic investigations. Cartesian meditations. The crises of European sciences and transcendental phenomenology. The crisis of European man and philosophy. Philosophy as rigorous science (AST, Moscow, 2000)

3. G. Harman, Immaterialism. Objects and Social Theory (Gaidar Institute, Moscow, 2018)

4. N. A. Nosov, Virtual psychology (Agraf, Moscow, 2000)

5. M. A. Pronin, Virtualistics in the Institute of Human Studies (Russian Academy of Science, Moscow, 2015)

6. M. A. Pronin, Existence: Forgotten Chernobyl: Liquidator's notes: A philosophicalanthropological essay (Kanon+, Moscow, 2016)

7. S. L. Frank, A subject of knowledge. Human sole (AST, Moscow, 2000)

8. O. D. Shipunova, L. I. Evseeva, Philosophy of communication: University education in sociocultural dynamics of information society (Saint Petersburg Polytechnic University, Saint Petersburg, 2015) 